\title{
ASPEK TEKNIS DAN EKONOMIS PENYARADAN DENGAN MENGGUNAKAN PANCANG TARIK (MONOCABLE WINCH) DI PT BELAYAN RIVER TIMBER
}

(Tehnical and Economical Aspects of Skidding with Monocable Winch System (Pancang Tarik Machine) in PT Belayan River Timber)

Oleh/By:

\section{Yosep Ruslim}

\section{Program Studi Kehutanan Fakultas Kehutanan Universitas Mulawaraman}

\begin{abstract}
Application of monocable winch (Pancang Tarik) system in Reduced Impact Logging (RIL) is an effort to reduce economical and environment damages if compared with ground based skidding with bulldozer system.

The aim of this research was to verify the efficiency (operational cost), effectiveness (productivity) and time consumption of monocable winch system. The implementation of monocable winch system in the slope of $<26 \%$ than that of $\geq 26 \%$, has resulted in the slight different of skidding cost and productivity. The operational cost has also indicated a non significantly different i.e. Rp. 31,000 ,- per cubicmetre on $<26 \%$ slope compare to Rp. 32,000,-per cubicmetre on $\geq 26 \%$ slope.

This figure is significantly cheaper if compare with the ground base skidding with bulldozer system in which the skidding cost around Rp. 175,000,- per cubicmetre.

The application of the monocable winch system therefore, promote better carbon sink, cost effective, environment friendly and reduce carbon emission.
\end{abstract}

Keyword : skidding, monocable winch, productivity, operasional skidding cost.

\begin{abstract}
ABSTRAK
Penerapan sistem Pancang Tarik (monocable winch) didalam kegiatan pemanenan ramah lingkungan (RIL) merupakan upaya untuk mengurangi biaya produksi dan mengurangi kerusakan lingkungan jika dibandingkan penyaradan dengan menggunakan sistem bulldoser.

Tujuan dari penelitian ini adalah untuk membuktikan bahwa penyaradan dengan menggunakan Pancang Tarik akan lebih efisien dan lebih produktif. Terdapat hanya sedikit perbedaan biaya penyaradan dan produktivitas penyaradan pada kelerengan $<26 \%$ dan kelerengan $\geq 26 \%$. Biaya operasional penyaradan pada kelerengan tersebut juga menunjukan tidak ada perbedaan yang nyata yaitu sebesar Rp. 31.000,- pada kelerengan $<26 \%$ dan Rp. 32.000,- pada kelerengan $\geq 26 \%$.
\end{abstract}


Hal tersebut menggambarkan bahwa penyaradan dengan menggunakan Pancang Tarik akan lebih murah jika dibandingkan penyaradan dengan menggunakan bulldoser yaitu sebesar Rp. $175.000,-/ \mathrm{m}^{3}$.

Penerapan sistem Pancang Tarik ini akan menghasilkan biaya penyaradan yang lebih efektif, ramah lingkungan dan mengurangi emisi karbon.

\section{Kata Kunci : pancang tarik, produktivitas, biaya operasional penyaradan.}

\section{PENDAHULUAN}

Teknik penyaradan kayu yang dengan menggunakan tenaga uap sudah dikenal di negara Amerika sejak tahun 1880 yang dikenal dengan nama "Steam Donkey Engine". Alat serupa ini juga sudah dikembangkan di Jerman sejak tahun 1926 untuk mengangkut kayu-kayu dari hasil pemanenan dengan menggunakan sistem kabel. Sedangkan di Indonesia pembalakan di hutan alam dimulai sejak tahun tujuh puluhan, awalnya dengan menggunakan tenaga hewan, manusia dan akhirnya dengan cara mekanis antara lain dengan bulldoser, sitem kabel, skidder dll. Sampai saat ini alat sarad bulldoser dianggap sebagai alat sarad yang paling sesuai untuk digunakan dalam pengelolaan hutan alam dengan sistem silvikultur Tebang Pilih Tanam Indonesia (TPTI).

Kegiatan pembalakan di Kalimantan Timur yang umum dilakukan oleh unit manajemen adalah dengan ground based skidding atau menggunakan bulldoser/traktor sebagai alat utama dalam proses penyaradan kayu. Walaupun dalam implementasinya alat pembalakan ini dapat diupayakan untuk meminimalkan dampak kerusakan lingkungan (terhadap tanah dan keterbukaan hutan) yaitu dengan mengimplementasikan pembalakan berdampak rendah (Reduced Impact Logging), namun masih dirasakan belum memberikan hasil yang maksimal, terutama dalam hal minimalisasi dampak lingkungan pada medan yang bertopografi sedang sampai bergelombang berat.

Akan tetapi dengan terus semakin tingginya harga bahan bakar minyak (BBM) maka biaya produksi dengan menggunakan bulldoser akan semakin tinggi, sehingga penggunaan alat Pancang Tarik dengan menggunakan kemampuan masyarakat lokal untuk dipekerjakan secara legal di HPH dan untuk menjaga hutan alam yang masih produktif dipandang perlu untuk diujicobakan.

Kegiatan penyaradan di hutan alam umumnya menggunakan alat berat berupa bulldoser. Kelebihan penggunaan bulldoser pada kegiatan penyaradan antara lain jarak sarad tidak terbatas dan lebih fleksibel ditinjau dari segi ekonomis, sedangkan kelemahannya adalah bulldoser tidak dapat digunakan pada daerah berawa, tidak dapat dioperasikan pada berbagai musim dan tidak dapat dipergunakan pada daerah dengan kelerengan $>40 \%$ (Anonim, 1996). Selain itu juga hasil-hasil 
penelitian yang ada menunjukan bahwa bulldoser menimbulkan dampak kerusakan yang besar baik itu kerusakan tegakan tinggal maupun keterbukaan lahan akibat kegiatan penyaradan secara khusus dan kegiatan pemanenan kayu secara umum (Ruslim et al. 2000, Holmes et al. 2001 dan Putz et al. 2008).

Alat Pancang Tarik sudah dikenal oleh masyarakat lokal di Kalimantan Timur untuk digunakan untuk menyarad log di hutan alam dan juga digunakan pada hutan tanaman industri, bahkan sudah digunakan dalam proses penyaradan di hutan rawa. Penggunaaan alat ini cukup banyak di lapangan oleh masyarakat karena nilai investasinya murah, mudah dalam pengoperasiannya di lapangan, pengangkutan dan pemeliharaannya.

Pada saat ini kegiatan pemanenan kayu dalam suatu areal IUPHHK Hutan Alam maupun Hutan Tanaman harus mempertimbangkan pada alat pembalakan yang efisien, berproduktivitas tinggi, ramah sosial serta ramah lingkungan. Improvisasi metode pembalakan yang efesien, ramah sosial dan ramah lingkungan harus selalu dilakukan sepanjang waktu oleh unit mananjemen hutan dalam rangka mencapai tujuan pengelolaan hutan yang berkesinambungan dalam segala aspek.

Berdasarkan uraian di atas, tujuan dari penelitian ini adalah mengetahui cara kerja penyaradan sistem monokabel menggunakan mesin Pancang Tarik, waktu kerja penyaradan, besarnya biaya operasional penyaradan serta produktivitas penyaradan pada kelerengan antara 0 $26 \%$ dan $\geq 26 \%$. Hasil yang diharapkan adalah penelitian ini dapat memberikan informasi tentang cara kerja, produktivitas serta biaya penyaradan dengan menggunakan sistem Pancang Tarik serta kelebihan dan kelemahan penyaradannya.

\section{A. Gambaran Umum Mesin Pancang Tarik}

Sesuai dengan namanya, pada awalnya mesin pancang yang digunakan masyarakat untuk penyaradan kayu ini dikenal sebagai alat pancang konstruksi bangunan, jembatan dan digunakan untuk menarik kapal dipelabuhan. Pada penggunaannya, mesin pancang tarik yang terdiri dari beberapa gear yang kekuatannya digerakkan dengan sebuah mesin generator (Dong Feng, Inda, Yanmar dll.) untuk menarik beban yang berfungsi sebagai penumbuk slope vertikal untuk konstruksi bangunan rumah ataupun jembatan. Mesin Pancang Tarik ini dimodifikasi, yaitu dengan menambah rangkaian gear yang lebih banyak sekitar 6 buah gear, sehingga dihasilkan tenaga yang lebih besar dalam menyarad kayu. Selain itu mesin pancang ini juga telah dimodifikasi dengan memanfaatkan gardan truk yang juga digerakan oleh mesin generator. Untuk penggunaan penyaradan kayu di hutan tanaman alat ini dilengkapi dengan tiang setinggi kurang lebih 4 meter untuk memudahkan pada saat penyaradan.

Spesifikasi mesin pancang yang digunakan dalam pengamatan ini meliputi mesin penggerak bermerk Dong Feng dengan kekuatan 22 PK, kemudian alat ini juga dilengkapi dengan 6 roda gigi dimana roda gigi tersebut sebagian ada yang berfungsi sebagai penggerak roda gigi yang 
lain serta sling berdiameter $3 / 4$ inch. Bahan bakar yang digunakan solar. Pada tahun 2010 harga satu set alat yang terdiri dari badan alat, mesin Don Feng dan sling sepanjang 100 meter berkisar antara Rp 40.000.000,-.

Sedangkan tipe mesin pancang yang digunakan dalam penelitian ini seperti yang terlihat pada Gambar 1 (Hertianti, 2005).

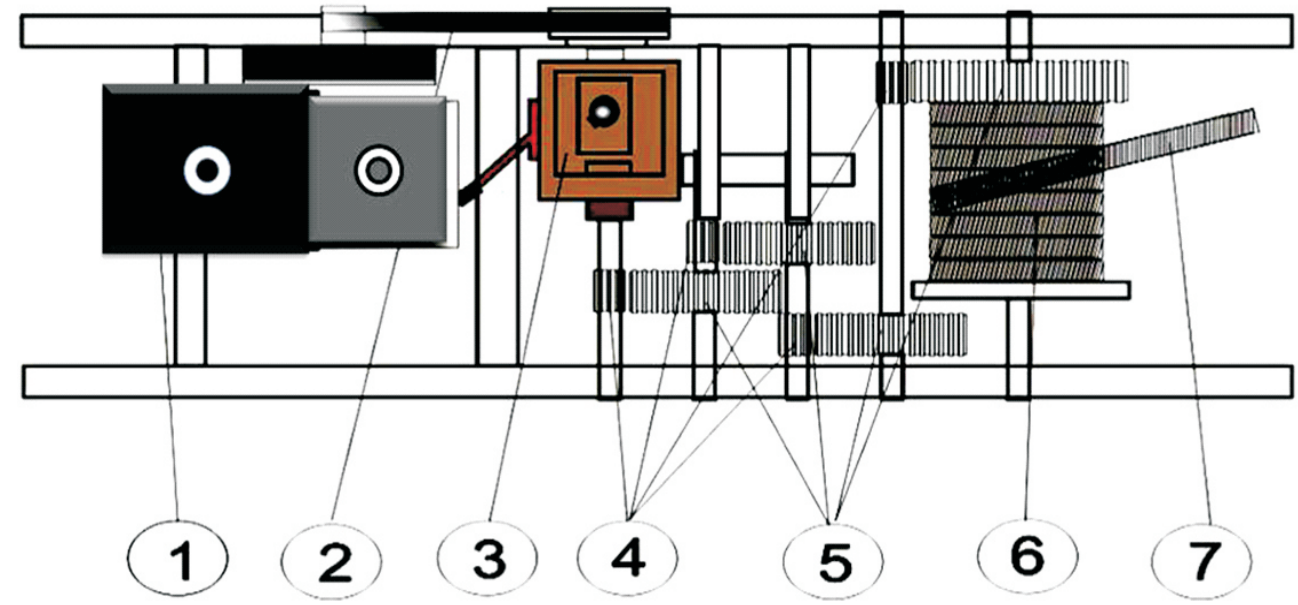

\section{Mesin Penggerak (Dong Feng) \\ 2. Van Belt \\ 6. Drum Roll \\ 3. Transmisi (gearbox) \\ 4. Drive Gear \\ 5. Driven Gear}

Gambar (Figure) 1. Sketsa alat mesin Pancang Tarik (monocable winch).

\section{B. Tahapan Kegiatan Mesin Pancang}

Prinsip kerja penyaradan kayu dengan Unit Pancang Tarik adalah sebagai berikut:

1. Spesifikasi Mesin Pancang Tarik

Spesifikasi mesin Pancang Tarik yang digunakan meliputi mesin penggerak merk Donfeng/Inda/Yanmar dengan kekuatan 22 PK, kemudian alat ini juga dilengkapi dengan 6 roda gigi (gear) dengan bahan bakar solar.

\section{Moving Unit Pancang Tarik}

Alat Pancang Tarik dibawa ke lokasi penebangan berdasarkan hasil undian anak petak yang telah diperoleh regu Pancang Tarik. Alat ini berjalan secara manual dengan cara menghidupkan mesin, kabel winch diulurkan antara 5-10 m dan diikatkan ke salah satu pohon yang terletak di jalur sarad yang telah ditandai sebelumnya. Kabel winch digulung secara perlahan-lahan sampai mendekati pohon yang dituju. Setelah itu lepas ikatannya lalu ulurkan kabel sling tersebut sampai ke titik sasaran pada pohon berikutnya. Kegiatan ini dilakukan sampai menuju etape yang terjauh 
dari jalan. Hal ini bertujuan agar batang-batang yang telah ditebang tidak mengganggu atau merintangi jalur sarad pada saat proses penyaradan berlangsung.

3. Gelagar/landasan dan pohon yang kokoh disiapkan untuk meletakan dan mengikatkan alat Pancang Tarik. Selanjutnya unit Pancang Tarik ditambat pada pohon yang dijamin kokoh dan tidak roboh oleh gaya tarik Unit Pancang Tarik dan beban dari log pada saat penyaradan berlansung. Diperkirakan posisi pohon yang dipilih sebagai pohon tambat dapat dipergunakan untuk menarik semua kayu atau sebagian besar kayu-kayu yang telah ditebang.

Lubang dibuat pada bagian banir atau koakan untuk memasang kabel sling, sehingga kabel sling tidak mudah bergerak. Setelah Unit Pancang Tarik terikat dengan kencang, lalu kabel sling diikat dengan baut skrup. Unit Pancang Tarik harus dipastikan untuk tidak bergerak pada saat penarikan kayu dimulai.

\section{Persiapan Alat}

Sebelum dilakukan proses penyaradan, maka operator melakukan pengisian bahan bakar sebanyak 5 liter dan mengisi air pendingin. Setelah itu dilakukan pemanasan alat sambil memberikan minyak pelumas pada semua gear yang berputar, agar proses penyaradan dapat berjalan dengan lancar.

\section{Penebangan}

- Penebangan dilakukan terlebih dahulu pada pohon yang terjauh dalam satu trayek penyaradan, agar tajuk yang ditingalkan tidak mengganggu penyaradan berikutnya.

- Arah rebah diupayakan membelakangi arah penyaradan dan arah rebahnya diupayakan sejajar dengan jalur sarad.

- Setelah pohon tumbang maka dilakukan trimming dan bucking menurut aturan pemotongan yang berlaku di perusahaan. Selain juga mempertimbangkan kemampuan Unit Pancang Tarik untuk menyarad yang disesuaikan dengan dimensi, jenis kayu yang disarad.

- Mengambil ekolin merah untuk ditempelkan ditunggak, dibontos kayu dan dibawa untuk diserahkan ke Mandor Tebang.

- Meruncingkan salah satu ujung batang yang terdekat dengan Unit Pancang Tarik, agar pada saat penyaradan ujung kayu tidak menggaruk permukaan tanah terlalu dalam yang akan menghindari putusnya kabel sling. Peruncingan dilakukan seminimal mungkin $( \pm 20 \mathrm{~cm})$ agar volume kayu yang didapat lebih banyak.

- Proses pemotongan pangkal batang ini hanya boleh dilakukan di Tpn.

- Hidupkan dan panaskan mesin Pancang Tarik, ulurkan kabel sling secara perlahan-lahan. Tahap selanjutnya hook man akan menarik hook dan kabel sling dan mengikatkan sling pada kayu yang disarad. Hookman memberikan aba-aba kepada operator mesin Pancang Tarik 
untuk segera menarik kayu tersebut secara perlahan-lahan. Pada saat posisi batang yang letaknya melintang dari jalur sarad ataupun menyangkut pohon, biasanya hookman segera memberikan aba-aba stop dan memindahkan posisi hook ketengah ataupun ke posisi belakang yang disesuaikan posisi batang.

\section{METODE PENELITIAN}

\section{A. LOKASI, WAKTU DAN OBJEK PENELITIAN.}

Penelitian penyaradan kayu dengan sistem Pancang Tarik (monocable winch) dilaksanakan di Unit Manajemen IUPHHK PT Belayan River Timber berdasarkan Administrasi Pemerintahan : Kabupaten Kutai Kartanegara, Kutai Barat dan Kutai Timur Propinsi Kalimantan Timur. Sedangkan berdasarkan kelompok hutannya IUPHHK masuk dalam Kelompok Hutan Sungai Senyiur Hulu, Kelompok Hutan Sungai Len - Sungai Belayan dan Kelompok Hutan Sungai Merah Hulu (Gambar 2).

Letak geografis PT. Belayan River Timber : 0 32’35”- $0^{\circ} 55^{\prime} 35^{\prime \prime}$ Lintang Utara, $115^{\circ} 30^{\prime}$ $22-116^{\circ} 11$ '38” Bujur Timur, dengan batas-batas areal kerja:

- Sebelahutara : PT. Wana Rimba Kencana, PT. Mutiara Kalja Permai

- Sebelah timur : PT. Melapi Timber dan PT. Mutiara Kalja Permai

- Sebelahselatan : Eks PT.Tunggal Yudi Timber, KUD Beringin Mulya, PT. Jatitrin, PT. Limbang Ganeca, eks PT. Limbang Praja dan PT. Melapi Timber

- Sebelahbarat : Eks PT.Gunung Jati Rimba, PT. Hitayaq Alan Medang dan PT. Barito Nusantara Indah. 


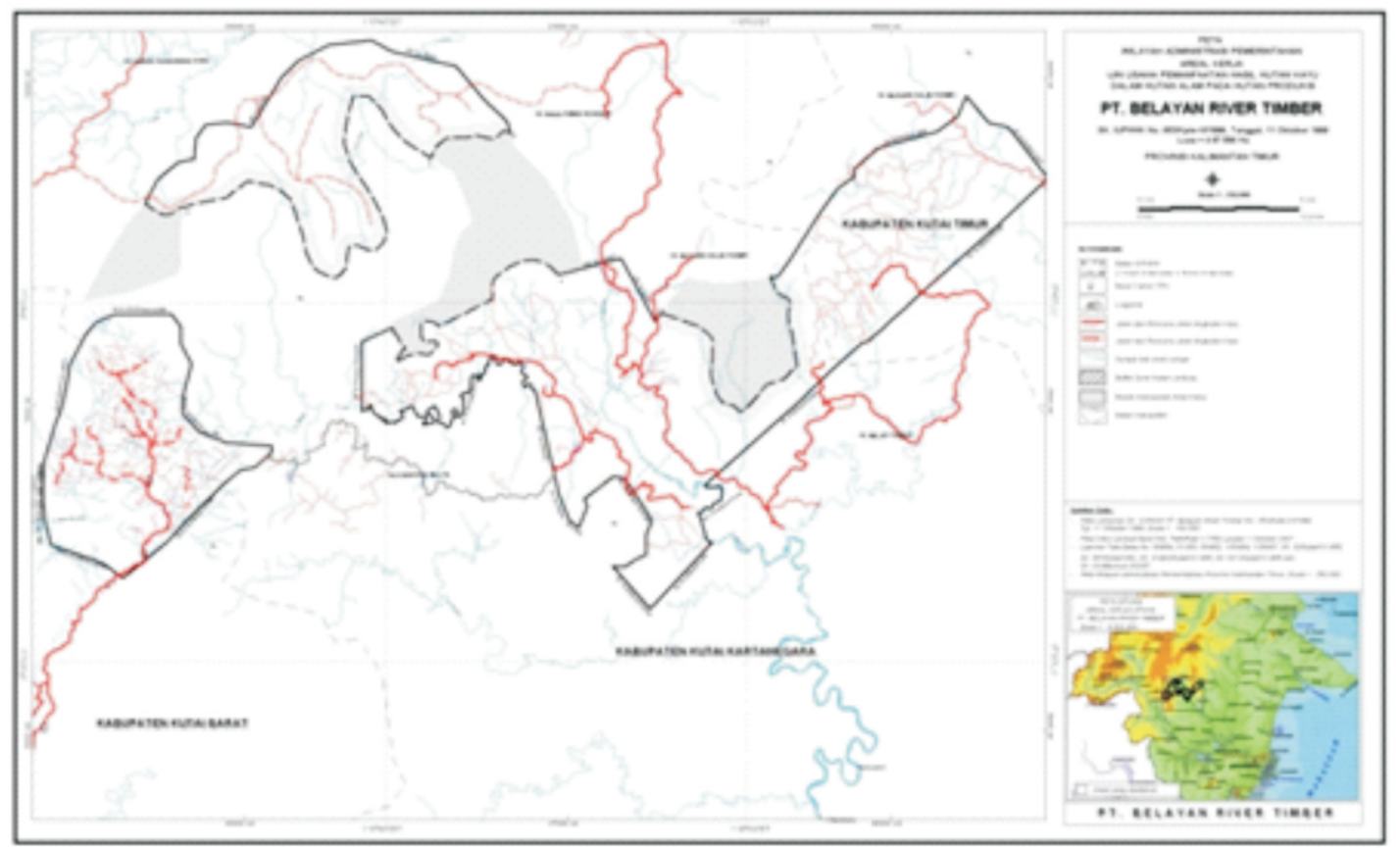

Gambar (Figure) 2. Peta Wilayah Administrasi Pemerintahan IUPHHK PT Belayan River Timber (Map of PT Belayan River Timber concession).

Waktu efektif yang diperlukan untuk melaksanakan penelitian ini selama kurang lebih 2 (dua) bulan. Obyek yang diamati pada penelitian ini adalah penyaradan sistem Pancang Tarik dengan menggunakan mesin Pancang Tarik dan rangkaian kegiatan operasionalnya. Kegiatan pertama yang dilakukan adalah persiapan meliputi orientasi lapangan dan proses diskusi dengan pengguna dimasyarakat dengan melakukan pengumpulan data baik melalui pengamatan langsung maupun tidak langsung.

\section{B. BAHAN DAN ALAT PENELITIAN}

Bahan dan alat yang diunakan dalam penelitian ini adalah : mesin Pancang Tarik, stopwatch, kompas, clinometer, meteran, kamera dan tally sheet.Untuk mendapatkan waktu kerja digunakan metoda Non Stop (persiapan alat, pembuatan jalan setapak untuk kayu, pengikatan mesin pancang pada tunggul kayu atau pohon berdiri, penarikan sling menuju kayu, pengikatan sling pada kayu yang akan disarad dengan menggunakan hook, penarikan kayu, pelepasan hook, penyusunan log dan penggulungan sling). Selain itu dilakukan pengukuran jarak sarad, pengukuran panjang dan diameter pangkal dan ujung kayu yang disarad. Data pendukung lainnya adalah peta penyebaran pohon, spesifikasi peralatan penyaradan menggunakan mesin Pancang Tarik, harga peralatan, bahan bakar, oli dan gemuk dan data lain yang berkaitan dengan penelitian. 


\section{PROSEDUR PENELITIAN}

1. Persiapan

Kegiatan yang dilakukan meliputi:

a. Orientasi lapangan

b. Pemilihan Petak Penelitian pada kondisi yang sedang dan bergelombang.

\section{Pengumpulan Data}

a. Pengamatan langsung di lapangan untuk mendapatkan data utama:

- Pencatatan rangkaian kegiatan penyaradan kayu dengan menggunakan mesin Pancang Tarik.

- Pengukuran kelerengan dari masing-masing jalur pada saat proses penyaradan berlangsung.

- Pengukuran waktu kerja dengan menggunakan metoda Non Stop (persiapan alat, pembuatan jalan setapak untuk kayu, pengikatan mesin pancang pada tunggul kayu atau pohon berdiri, penarikan sling menuju kayu, pengikatan sling pada kayu yang akan disarad dengan menggunakan hook, penarikan kayu, pelepasan hook, penyusunan log dan penggulungan sling).

- Pengukuran jarak sarad.

- Pengukuran panjang dan diameter pangkal dan ujung kayu yang disarad

- Pengukuran panjang peruncingan.

b. Pengamatan tidak langsung untuk mendapatkan data penunjang.

- Peta penyebaran pohon dan peta kontur.

- Spesifikasi peralatan penyaradan menggunakan mesin Pancang Tarik.

- Harga peralatan, bahan bakar, oli dan gemuk.

- Data lain yang berkaitan dengan penelitian.

\section{PENGOLAHAN DATA}

1. Produktivitas Penyaradan

Produktivitas penyaradan dihitung dengan menggunakan rumus Brown(1958):

$$
\mathrm{P}=\frac{\sum \mathrm{V}}{\mathrm{Wa}+\mathrm{Wo}+\mathrm{Wb}}
$$

Keterangan:

$\mathrm{P}=$ Produktivitas penyaradan $\left(\mathrm{m}^{3} / \mathrm{jam}\right)$

$\mathrm{V}=$ volume kayu yang disarad per trip $\left(\mathrm{m}^{3} /\right.$ trip$)$

$\mathrm{Wa}=$ waktu persiapan dan pemasangan alat (jam) 
Wo $=$ waktu operasi (jam)

$\mathrm{Wb}=$ waktu pemindahan dan pembongkaran alat (jam)

$\mathrm{N}=$ jumlah trip

Volume kayu yang disarad dengan menggunakan rumus:

$$
V=1 / 4 \pi \bar{D}^{2} \times L
$$

Keterangan:

$\mathrm{V}=$ volume kayu yang disarad $\left(\mathrm{m}^{3}\right)$

$\bar{D}=$ diamater rataan dari pangkal dan ujung pohon $(\mathrm{cm})$

$\mathrm{L}=$ panjang kayu yang disarad $(\mathrm{m})$

$\pi=3,14$

2. Biaya Penyaradan

a. Biaya Tetap

a.1. Depresisasi

Depresiasi dihitung dengan menggunakan straight line depreciation (Newman, 1988).

$$
\mathrm{D}=\frac{\mathrm{M}-\mathrm{R}}{\mathrm{N}}
$$

Keterangan:

$\mathrm{D}=$ depresiasi tahunan $(\mathrm{Rp} / \mathrm{thn})$

$\mathrm{M}=$ harga alat $(\mathrm{Rp})$

$\mathrm{R}=$ nilai rongsokan $(\mathrm{Rp})$

$\mathrm{N}=$ masa pakai (thn)

a.2. Bunga modal, pajak dan asuransi

Bunga modal dan pajak dan asuransi dihitung dengan menggunakan rumus average investment interest (Wiradinata, 1981):

$$
\mathrm{B}=\frac{(\mathrm{M}-\mathrm{R})(\mathrm{N}-1)}{2 \mathrm{~N}}+R \times 0,0 p
$$

Keterangan:

$\mathrm{B}=$ bunga modal pertahun

$0,0 \mathrm{p}=$ bunga pertahun $(\%)$ 
b. Biaya Tidak Tetap

b.1. Biaya operasi

- Biaya pemeliharaan dan perbaikan

- Biaya bahan bakar, oli dan pelumas

- Biaya sling

b.2. Upah

b.3. Biaya pemindahan alat

b.4. Biaya makan dan personal use

b.5. Biaya perlengkapan

\section{HASIL PENELITIAN DAN PEMBAHASAN}

\section{A. Analisa Biaya Penyaradan Dengan Mesin Pancang}

Hasil perhitungan berdasarkan standard biaya tahun 2010 menunjukkan bahwa untuk menghasilkan $1 \mathrm{~m}^{3}$ kayu tebangan dibutuhkan biaya tetap sebesar Rp. 18.596,- (diperoleh dari besar biaya penyusutan Rp. 3.860,- per batang; bunga, pajak dan asuransi sebesar Rp. 14.736,- per batang) dan biaya tidak tetap sebesar Rp. 72.504,- (diperoleh dari penggunaan solar Rp. 4.375,- per jam; oli Rp. 750,- per jam; sling Rp. 8.333,--per meter, biaya makan Rp. 35.000,- per orang; biaya perbaikan alat Rp. 5.000,- per jam).

Besarnya pengupahan diatur sebagai berikut: dari Rp. 95.000,- upah yang diterima akan dibagi menjadi dua bagian, yaitu Rp. 75.000,- untuk upah tim pancang dan Rp. 20.000,- untuk kontraktor (penanggung jawab pekerjaan). Dari Rp. 75.000,- yang diterima tim pancang akan dibagi 7 bagian secara merata, dimana 5 orang yang bekerja menerima upah 5 bagian serta 2 bagian sebagai upah si pemilik mesin pancang dan pemilik chainsaw sehingga setiap bagian akan menerima upah sebesar Rp. 10.714,--

Secara rinci perhitungan biaya per $\mathrm{m}^{3}$ kayu dapat dilihat pada Tabel 1 berikut: 
Tabel (Table) 1.Biaya Penyaradan dengan Mesin Pancang Tarik (Skidding Cost with Pancang Tarik Maschine).

\begin{tabular}{|c|c|c|}
\hline No. & $\begin{array}{l}\text { Komponen Biaya } \\
\text { (Cost Component) }\end{array}$ & $\begin{array}{l}\text { Jumlah } \\
\text { (Total) }\end{array}$ \\
\hline 1. & $\begin{array}{l}\text { Biaya Tetap } \\
\text { (Fix Cost) }\end{array}$ & \\
\hline a. & $\begin{array}{l}\text { Penyusutan/Depreciation } \\
=\frac{40.000 .000-1.400 .000}{5}=\text { Rp. } 7.720 .000,- \text { per } 2000 \mathrm{jam}\end{array}$ & Rp. 3.860,-/jam \\
\hline b. & $\begin{array}{l}\text { Bunga, pajak dan asuransi/Interest, Insurance and taxes } \\
=\frac{\{(40.000 .000-1.400 .000)(5+1)+1.400 .000\} \times 1,2}{2 \times 5} \\
=\text { Rp. } 29.472 .000 / 2000 \mathrm{jam}\end{array}$ & Rp. 14.736,-/jam \\
\hline c. & $\begin{array}{l}\text { Biaya pemindahan alat/Transportation cost } \\
\text { Rp. } 1.500 .000 /(5 \mathrm{thn})=\text { Rp. } 300.000 / 2.000 \mathrm{jam} / \text { tahun }\end{array}$ & Rp. $\quad 150,-$ \\
\hline & Biaya Tetap $(\mathrm{a}+\mathrm{b}+\mathrm{c}) /$ Fix Cost $(a+b+c)$ & Rp. 18.746.-/jam \\
\hline 2. & Biaya Tidak Tetap (Variable Cost) & \\
\hline a. & Solar 5 liter/hari@ @p. 7.000,-/liter=Rp.35.000,-/8 jam & Rp. $4.375,-/$ jam \\
\hline b. & Oli/Oil 10 liter/bulan@ @ Rp.15.000,-=Rp.15.000,-/2000 & Rp. $\quad 750,-/$ jam \\
\hline c. & $\begin{array}{l}\text { Sling/Wire rope } 100 \mathrm{~m} / 3 \text { bulan @ Rp. 5.000.000,- = Rp. } \\
5.000 .000,-/(3 \times 200 \mathrm{jam})\end{array}$ & Rp. $8.333,-/$ jam \\
\hline d. & $\begin{array}{l}\text { Biaya makan/Personal Cost per team = Rp. } 7.000 .000,-/ 200 \\
\text { jam }\end{array}$ & Rp. 35.000,-/jam \\
\hline e. & $\begin{array}{l}\text { Biaya perbaikan alat/Maintenance Cost }=\text { Rp. } 1.000 .000,-/ 200 \\
\text { jam }\end{array}$ & Rp. $\quad 5.000,-/ \mathrm{jam}$ \\
\hline f. & Upah pekerja/Labour Cost $=\frac{\text { Rp.95.000,- - Rp.20.000,- }}{7}$ & Rp. $\quad 10.714,-$ \\
\hline & Total Biaya Tidak Tetap ( Total of Variable Cost) & Rp. 64.172,-/jam \\
\hline & Total biaya keseluruhan ( Grand Total of Cost) & \\
\hline & Rp. 18.746.- + Rp. 64.172,- & Rp. 82.918/jam \\
\hline
\end{tabular}


Produktivitas untuk waktu kerja total pada kegiatan penyaradan kayu dengan menggunakan mesin Pancang Tarik pada kelerengan lebih kecil 26\% sebesar 6,92 $\mathrm{m}^{3} / \mathrm{jam} / \mathrm{hm}$ dengan biaya penyaradan sebesar Rp. 11.982/ $\mathrm{m}^{3} / \mathrm{hm}$, sedangkan untuk kelerengan yang lebih besar dari $26 \%$ adalah sebesar $=6,43 \mathrm{~m}^{3} / \mathrm{jam} / \mathrm{hm}$ dengan biaya penyaradan sebesar Rp. $12.895 / \mathrm{m}^{3} / \mathrm{hm}$. Sedangan produktivitas per hm untuk waktu kerja murni pada kegiatan penyaradan kayu dengan menggunakan mesin Pancang Tarik pada kelerengan lebih kecil 26\% sebesar 7,9 $\mathrm{m}^{3} / \mathrm{jam} / \mathrm{hm}$ dengan biaya penyaradan sebesar Rp. $10.495 / \mathrm{m}^{3} / \mathrm{hm}$ sedangkan untuk kelerengan yang lebih besar dari 26 $\%$ adalah sebesar $=7,8 \mathrm{~m}^{3} / \mathrm{jam} / \mathrm{hm}$ dengan biaya penyaradan sebesar Rp. $10.630 / \mathrm{m}^{3} / \mathrm{hm}$. Dengan demikian biaya yang dikeluarkan berdasarkan waktu kerja murni untuk mengeluarkan $1 \mathrm{~m}^{3} \mathrm{kayu}$ dengan jarak sarad rataan $300 \mathrm{~m}$ pada kelerengan lebih kecil dari $26 \%$ adalah sebesar Rp. $31.000,-/ \mathrm{m}^{3}$ dan pada kelerengan lebih besar dari $26 \%$ adalah sebesar $\mathrm{Rp} 32.000,-/ \mathrm{m}^{3}$.

\section{B. Analisi Teknis}

Dari hasil pengamatan di lapangan, kerusakan tegakan tinggal dan keterbukaan lahan yang diakibatkan oleh operasional mesin Pancang Tarik ini sangat kecil jika dibandingkan dengan operasional bulldoser bahkan jika dibandingkan dengan operasional sistem skyline. Kelebihan lain dari alat ini adalah dapat mengambil kayu-kayu hasil tebangan pada medan yang berbatu dan pada lorong-lorong sempit, dimana bulldoser tidak dapat masuk atau menjangkaunya. Berbeda dengan penyaradan dengan bulldoser dan skyline, operasional mesin Pancang Tarik akan menarik kayu berada di atas tanah dengan pangkal kayu dibentuk setengah lingkaran sehingga akan mudah berjalan/melintas disela-sela pohon pada saat operasional penyaradannya. Hal ini mengakibatkan jalur yang terbuka pada lintasannya jauh lebih kecil dari jalur skyline, yaitu hanya selebar diameter kayu saja.

Penggunaan operasional pembalakan dengan Pancang Tarik memerlukan banyak tenaga kerja terutama jika dibandingkan dengan dengan operasional bulldoser logging. Kemampuan ratarata penyaradan dengan alat Pancang Tarik rata-rata 5 batang/hari, sehingga untuk menghasilkan keluaran (output) per satuan waktu dari Pancang Tarik ini, diperlukan jumlah alat Pancang Tarik yang digunakan menjadi lebih banyak, hal ini mempunyai implikasi jumlah tenaga kerja yang dibutuhkan jika menggunakan alat Pancang Tarik menjadi semakin banyak. 


\section{KESIMPULAN}

1. Biaya penyaradan yang dikeluarkan berdasarkan waktu kerja murni untuk mengeluarkan $1 \mathrm{~m}^{3}$ kayu dengan jarak sarad rataan 300 m pada kelerengan < dari $26 \%$ adalah sebesar Rp. 31.000,-/ $\mathrm{m}^{3}$ dan pada kelerengan $\geq 26 \%$ adalah sebesar $\mathrm{Rp} 32.000,-/ \mathrm{m}^{3}$

2. Mesin Pancang Tarik merupakan alternatif yang terbaik didalam sistem pemanenan lainnya, baik ditinjau dari aspek lingkungan, ekonomi, maupun dari aspek teknis.

\section{DAFTAR PUSTAKA}

Anonim. 1996., FAO Model Code of Forest Harvesting Practices, FAO, Rome.

Hertianti, E. 2005. Studi Penyaradan Kayu dengan Sistem Monokabel (Mesin Pancang) di Kampung Sungai Linuq Kecamatan Tabang Kabupaten Kutai Kertanegara. Tesis Pasca Sarjana Unmul. Samarinda.

Holmes T. P., Boltz, F., dan Carter, D. R. 2001. Financial Indicators of Reduced Impact Logging Performance in Brazil. FAO. Bangkok. Tahiland.

Newman, D. G. 1988. Engineering Economic Analysis. $3^{\text {rd }}$ Edition. Binarupa Aksara Engineering Press. Inc. Jakarta.

Pinard, M.A., Putz, F. E. and Tay, J. 2000. Lessons Learned From the Implementation of Reduced Impact Logging in Hilly Terrain in Sabah, Malayasia.

Putz, F.E., Sist, P., Fredericksen, T. and Dykstra, D. 2008. Reduced Impact Logging: Challenges and oppurtunities. Forest Ecology and Management.

Ruchanda, A. 1993. Studi Komposisi dan Struktur Tegakan Sebelum dan Sesudah Pemanenan Kayu dengan Sistem Silvikultur Tebang Pilih Tanam Indonesia (TPTI) di Areal HPH PT. Narkata Rimba (Alas Kusuma Grup) Kalimantan Timur.

Ruslim, Y., Hinrichs. A. dan Sulistioadi, B. 2000. Studi Implementasi Reduced Impact Tractor Logging. SFMP Document No. 01b.

Ruslim, Y. Rachmat, M. dan Hertianti E. 2008. Studi Penyaradan Kayu Dengan Sistem Monokabel (Mesin Pancang) Di Kampung Sungai Lunuq Kecamatan Tabang Kabupaten Kutai Kartanegara. Jurnal Magister Pertanian Universitas Mulawarman.

Tinambunan, D. 2008. Teknologi Tepat Guna Dalam Pemanenan Hutan di Indonesia: Perkembangan Keunggulan, Kelemahan, Dan Kebijaksanaan Yang Diperlukan Untuk 
Optimalisasi Pemanfaatannya. Jurnal Analisis Kebijakan Kehutanan. Vol. 5 No. 2, Agustus 2008: 59 - 7. Pusat Penelitian dan Pengembangan Hasil Hutan, Bogor.

Wiradinata, S. 1981. Pengantar Analisis Biaya Pembalakan. Fakultas Kehutanan IPB. Bogor. 